\title{
BIOLOGIA FLORAL E SISTEMA REPRODUTIVO DE Gliricidia sepium (JACQ.) STEUD. (FABACEAE- PAPILIONOIDAE) NA REGIÃO DE PETROLINA, PERNAMBUCO
}

\author{
FLORAL BIOLOGY AND REPRODUCTIVE SYSTEM OF Gliricidia sepium (JACQ.) STEUD. \\ (FABACEAE-PAPILIONOIDAE) IN REGION OF PETROLINA, PERNAMBUCO STATE, BRAZIL
}

\author{
Lúcia Helena Piedade Kiill $^{1}$ Marcos Antônio Drumond ${ }^{2}$
}

RESUMO

Aspectos da biologia da polinização e do sistema de reprodução de Gliricidia sepium foram estudados no período de março a dezembro de 1999, entre 05:30 e 17:00h., em uma população introduzida na Embrapa Semi-Árido (Petrolina, estado de Pernambuco). Quinze indivíduos da população foram marcados e acompanhados quinzenalmente para as observações dos estudos fenológicos. Para o estudo da morfologia e biologia florais, flores e inflorescências foram marcadas e acompanhadas até a formação dos frutos. Os visitantes florais foram observados ao longo do período do experimento, anotando-se a freqüência, o horário e a duração de suas visitas. G. sepium apresenta floração anual do tipo "cornucópia”, com pico desta fenofase no mês de agosto. As flores estão reunidas em racemos axilares, com desenvolvimento centrípeto, ocorrendo a antese de 5 a 45 flores/dia. As flores apresentam a formação típica das papilionáceas, com corola de cor magenta, com a parte central do estandarte de cor creme, o qual funciona como guia de néctar. A antese é diurna, ocorrendo por volta da 06:00h, e a duração das flores é de aproximadamente 10 horas. Abelhas Apidae e Anthophoridae e lepidópteros Hesperiidae são os visitantes mais freqüentes, sendo Xylocopa griscesens, X. frontalis e Eulaema nigrita consideradas como principais polinizadores desta espécie. Quanto ao sistema de reprodução, G. sepium é xenôgama obrigatória, produzindo frutos e sementes somente após polinização cruzada $(51,6 \%)$.

Palavras-chave: polinização, sistema de reprodução, Gliricidia sepium, frutificação e floração.

\section{SUMMARY}

The aspects of floral biology and reproductive system of Gliricidia sepium were studied from March to October of 1999, from 5:30am to 5:00pm, in an introduced population at Embrapa Semi-Árido, Petrolina, in the State of Pernambuco,
Brazil. Fifteen plants were marked and observed every two weeks for the study of phenology. For the study of floral biology and morphology, flowers and inflorescences were marked and observed until fruit set. The visitors of flowers were observed during all time of the experiment, when frequency, time and duration of their visits were registered. G. sepium has a cornucopia pattern of flowering and the peak of this phenophase occurs in August. The flowers are grouped in axilar racemes, with centripetal development, and the anthesis occurs at 5 to 45 flowers/day. The flowers have the typical organization of papilionaceae, corolla of magenta color and the central region of flag of cream color, which functions as nectar guide. The anthesis is diurnal, occurring at around 6:00am, and the lifetime of flowers is around 10 hours. Apidae and Anthophoridae bees and Hesperiidae moths are the most frequent visitors. Xylocopa griscesens, $X$. frontalis and Eulaema nigrita were considered the main pollinators of this species. $\boldsymbol{G}$. sepium is a species which produces fruits only after cross-pollination (51.6\%).

Key words: pollination, reproductive system, Gliricidia sepium, floration, frutification.

\section{INTRODUÇÃO}

Gliricidia sepium (Jacq.) Steud. é uma planta nativa da América do Sul e Central, com distribuição pelas regiões tropicais (SUMBERG, 1985). Segundo DUQUE (1998), esta espécie ocorre naturalmente do México até a Colômbia, Venezuela e Guianas. Desde os tempos pré-colombianos, $\boldsymbol{G}$. sepium já era cultivada além das áreas de ocorrência natural, tendo sido naturalizada em Cuba, Jamaica, Havaí, África Ocidental e Meridional, Índia, Siri Lanka, Tailândia, Filipinas, Indonésia e Austrália (PARROTTA, 1992).

\footnotetext{
${ }^{1}$ Bolsista DCR/CNPq, Embrapa Semi-Árido, BR428, Km 152, zona rural, CP 23, 56300-000, Petrolina, PE. E-mail: kiill@cpatsa.embrapa.br. Autor para correspondência.

${ }^{2}$ Pesquisador Embrapa Semi-Árido.
} 
Vulgarmente conhecida no Brasil como gliricídia, no México e em países da América Central como "madero negro, mata ratón, madre de cacao", G. sepium, é uma espécie de grande interesse comercial e econômico para regiões tropicais pelas suas características de uso múltiplo. Há vários anos, esta espécie vem sendo cultivada na região sudoeste da Bahia para o sombreamento do cacau, tendo sido recentemente introduzida nos estados de Pernambuco e Sergipe. Esta espécie se destaca por apresentar rápido crescimento, alta capacidade de regeneração, resistência à seca e facilidade em se propagar sexuada e assexuadamente. Vem sendo explorada como forrageira pelo seu alto valor nutritivo, como produtora de estacas vivas e, ainda, como alternativa energética (DRUMOND \& CARVALHO FILHO, 1999).

Estudos sobre a biologia floral de $\boldsymbol{G}$. sepium são relatados na Nigéria, nas Antilhas e no México. Segundo AKEN'OVA \& SUMBERG (1986), as abelhas Xylocopa albeceps e X. olivacea são consideradas como as principais polinizadoras da G. sepium em Ibadan (Nigéria). Já CORBET \& WILMER (1980) registraram visitas de $\boldsymbol{X}$. mondax nas Antilhas, enquanto JANZEN (1983) considerou $\boldsymbol{X}$. frimbriata como o polinizador primário de $\boldsymbol{G}$. sepium para a região do México e da América Central.

Com relação ao sistema de reprodução, AKEN'OVA \& SUMBERG (1986) registraram que a autopolinização espontânea não ocorre nesta espécie, necessitando de agentes polinizadores para seu êxito reprodutivo. SIMONS \& DUNSDON (1987) relataram que G. sepium é xenogâmica. O presente trabalho teve como objetivo estudar a biologia floral, a polinização e o sistema de reprodução de $\boldsymbol{G}$. sepium na região de Petrolina, Pernambuco.

\section{MATERIAL E MÉTODOS}

O presente trabalho foi desenvolvido na região da Embrapa Semi-Árido, município de Petrolina-PE (09 $09^{\prime} \mathrm{S}$; 4022'O, 350m.) que, de acordo com a classificação de Köppen, apresenta clima do tipo BSwh', definido como semi-árido (chuva anual inferior a $750 \mathrm{~mm}$ ), sem excesso hídrico. A umidade relativa é de $60 \%$, com precipitação média anual de $566,5 \mathrm{~mm}$. A estação chuvosa ocorre no período de novembro a abril, e a seca no período de maio a outubro. Os dados climáticos referentes ao período de realização deste trabalho estão na tabela 1 .
Tabela 1 - Dados climáticos da região de Petrolina, no período de março a dezembro de 1999, fornecidos pelo Embrapa Semi-Árido.

\begin{tabular}{lccc}
\hline $\begin{array}{l}\text { Meses do } \\
\text { Ano }\end{array}$ & $\begin{array}{c}\text { Temperatura } \\
\left({ }^{\mathrm{O} C}\right)\end{array}$ & $\begin{array}{c}\text { Umidade } \\
\%\end{array}$ & $\begin{array}{c}\text { Precipitação } \\
(\mathrm{mm})\end{array}$ \\
\hline Março & 26,8 & 74 & 64,3 \\
Abril & 27,7 & 61 & 5,0 \\
Maio & 26,0 & 62 & 12,8 \\
Junho & 25,6 & 59 & 0,0 \\
Julho & 24,5 & 60 & 2,1 \\
Agosto & 23,2 & 71 & 2,3 \\
Setembro & 25,2 & 66 & 30,4 \\
Outubro & 25,5 & 70 & 18,1 \\
Novembro & 26,1 & 70 & 97,2 \\
Dezembro & 25,3 & 82 & 133,8 \\
\hline
\end{tabular}

A população de $\boldsymbol{G}$. sepium utilizada no presente estudo foi formada por 50 indivíduos que foram introduzidos na região em 1985 através de estacas procedentes da CEPLAC, Itabuna-Bahia. As observações de campo foram desenvolvidas de março a dezembro de 1999, entre 05:30 e 17:00h. Para o estudo fenológico, 15 indivíduos da população foram marcados e acompanhados quinzenalmente. Dez inflorescências em cinco indivíduos da população foram marcadas e acompanhadas até a abertura da última flor para verificar a quantidade de flores formadas por inflorescência. Quinze flores recém-abertas foram coletadas aleatoriamente entre os indivíduos da população e mensuradas com auxílio de paquímetro para verificação do comprimento das peças da corola e das estruturas reprodutivas e a posição destas últimas no interior da flor. A viabilidade dos grãos de pólen foi verificada em cinco lâminas, onde todas as anteras de um botão em pré-antese foram esmagadas e preparadas com carmim acético 1,2\% (RADFORD et al., 1974) e 100 grãos de pólen foram analisados por lâmina, totalizando 500 grãos. A receptividade do estigma foi testada com Sudam III (JOHANSEN, 1940).

Os visitantes florais foram observados ao longo do período de floração, sendo anotadas a frequiência, a duração e o horário das visitas, bem como o comportamento dos mais freqüentes.

Para determinar a estratégia reprodutiva da espécie, flores foram ensacadas e submetidas aos experimentos de autopolinização espontânea e manual, apomixia e polinização cruzada. Flores sem cobertura e sem nenhum tratamento foram observadas para estimar o sucesso da polinização em condições naturais, servindo como controle. Para cada tratamento, foram utilizadas de 30 a 36 flores previamente ensacadas e emasculadas, quando necessário. $\mathrm{O}$ pólen usado em todos os testes foi 
obtido de flores ensacadas. Nestes experimentos, foram utilizadas flores próximas da região basal da inflorescência que, segundo BAWA \& WEBB (1984), são as que têm maior probabilidade de formação de frutos.

Para avaliar o número de frutos formados por inflorescência, 10 inflorescências foram marcadas e acompanhadas, anotando-se o número de frutos formados. O número de sementes/fruto também foi avaliado, utilizando-se para isso uma amostra de 20 frutos. As razões fruto/flor e semente/óvulo foram determinadas de acordo com o método descrito por BAWA \& BUCKLEY (1989), utilizando-se 20 flores. Materiais testemunhos foram depositados no Herbário do Trópico Semi-Árido (HTSA).

\section{RESULTADOS E DISCUSSÃO}

A floração da $\boldsymbol{G}$. sepium ocorreu no período de julho a outubro de 1999 , atingindo o pico no início de agosto. Comparando-se com os dados climáticos do período (Tabela 1), observa-se que a floração ocorreu ao longo da estação seca. Fato semelhante foi registrado por FRANCO (1995) para outras espécies desta família na região de Campinas (SP) e, segundo JANZEN (1967), a redução da umidade do solo e da umidade atmosférica podem agir como sinal para a floração de espécies de regiões tropicais. Quanto ao padrão de floração, esta espécie, por apresentar produção diária de muitas flores por planta com elevada sincronia intraespecífica em uma única estação do ano, é considerada como do tipo "cornucópia" e anual, de acordo com os padrões propostos por GENTRY (1974a e b) e NEWSTROM et al. (1994).

G. sepium apresenta flores reunidas em inflorescências axilares, do tipo racemo, com desenvolvimento centrípeto. O número de botões por inflorescência variou de 27 a 58, sendo registrados, em média 36 botões por inflorescência, concordando com os dados obtidos por SUMBERG (1985), que registrou médias de 18,2 a 40,1 botões/racemo. O número de flores abertas por inflorescência também variou, sendo encontradas inflorescências com 5 a 45 flores abertas por dia. A disponibilidade de muitas flores por inflorescência por dia é comum na família Fabaceae (FRANCO, 1995), sendo vantajosa para a espécie, pois aumenta a atratividade do polinizador, uma vez que há aumento na disponibilidade de néctar. A abertura das flores a partir da base da inflorescência é comum nesta família (AGULHO et al., 1993) e, de acordo com BAWA \& WEBB (1984), está relacionada com o fato destas primeiras flores apresentarem maior probabilidade de formar frutos do que as flores do ápice.

Quanto à morfologia, as flores de $\boldsymbol{G}$. sepium são do tipo papilionácea, sem ressupinamento. De acordo com FAEGRI \& PIJL (1980), são classificadas como do tipo estandarte, ono qual a morfologia floral seria derivada de forte adaptação à polinização por abelhas. As medidas e a coloração dos elementos florais estão agrupados na tabela 2. O cálice é gamossépalo formando um pequeno tubo que envolve a parte basal da corola. A corola apresenta pétalas com coloração magenta predominante e porção mediana do estandarte de cor creme que funciona como guia de néctar. $\mathrm{O}$ androceu é formado por dez estames diadelfos, com nove estames fundidos na região do filete, formando uma bainha estaminal. As anteras são bitecas, dorsifixas com deiscência longitudinal. $\mathrm{O}$ gineceu é envolvido pela bainha estaminal e apresenta ovário com dez óvulos, estilete simples e estigma lobado. $\mathrm{O}$ nectário se apresenta na forma de um disco hipógino.

A antese das flores é diurna (06:00h) e é caracterizada pela distensão e reflexão do estandarte, mostrando a prefloração coclear vexilar. Os órgãos reprodutivos permanecem inclusos na quilha, sendo expostos somente durante o contato com o visitante. No momento da antese, os grãos de pólen estão disponíveis nas anteras e apresentam viabilidade em torno de 98,6\%. O estigma está receptivo e há acúmulo de pequenas quantidades de néctar na base da corola. A emissão de odores não foi detectada. As flores permaneceram inalteradas até as 16:00h, quando iniciavam o processo de senescência floral, caracterizado pelo murchamento e a alteração da cor do estandarte. O tempo de vida da flor foi de 10 horas. Aproximadamente 24 horas após a antese ocorreu a queda dos elementos florais, exceto do cálice e ovário, se houve fecundação. G. sepium apresenta atributos florais como zigomorfia, cores vistosas, guias de néctar, antese diurna, plataforma de pouso e néctar abrigado na base da corola que,

Tabela 2 - Medidas (mm) e coloração dos elementos florais de Gliricidia sepium. Embrapa Semi-Arido, Petrolina-PE,1999.

\begin{tabular}{lcl}
\hline Elementos florais & Medidas $(\mathrm{X} \pm \mathrm{SD})$ & \multicolumn{1}{c}{ Coloração } \\
\hline Cálice & $5,41 \pm 0,50$ & Verde/vináceo \\
Corola & & \\
$\quad$ Estandarte/guias de néctar & $21,53 \pm 0,92$ & Magenta/creme \\
Ala & $19,80 \pm 1,26$ & Magenta \\
$\quad$ Quilha & $18,07 \pm 1,03$ & Magenta \\
Androceu & $16,87 \pm 0,92$ & Branco \\
Gineceu & $16,13 \pm 0,99$ & Branco/ vináceo \\
\hline
\end{tabular}


segundo FAEGRI \& PIJL (1980), são característicos da "Síndrome da Melitofilia", permitindo classificála como uma espécie melitófila.

Ao longo da floração, as flores de $\boldsymbol{G}$. sepium foram visitadas por abelhas Apidae e Anthophoridae e lepidópteros Hesperiidae (Tabela 3). As abelhas apresentaram maior número de espécies, sendo responsáveis por 51,9\% do total de visitas. Entre os visitantes florais, Urbanus proteus L. foi o mais frequiente, sendo responsável por $48,1 \%$ do total de visitas.

As abelhas Xylocopa griscesens Lep., $\boldsymbol{X}$. frontalis Olivier e Eulaema nigrita Lep. visitaram as flores de G. sepium durante todo o período de observação, com pico entre 07:00 e 09:00h. Com relação ao comportamento de visita, apresentaram semelhanças entre si, sobrevoando as inflorescências, pousando sobre uma das flores abertas. Após a aproximação da flor, pousavam sobre as alas deslocando-as para baixo. Simultaneamente empurravam, com a cabeça, o estandarte para trás e, posteriormente, introduziam a língua na base dos elementos florais para alcançar o néctar. Como consequiência, os órgãos reprodutivos das flores eram liberados das quilhas e contatavam a região ventral do corpo da abelha, onde o pólen ficava depositado, caracterizando a polinização esternotríbica.

Uma vez coletado o néctar, as abelhas caminhavam sobre a inflorescência, visitando outras flores disponíveis e, após a visita de 10 a 15 flores, levantavam vôo, visitando inflorescências próximas ou então abandonavam o local. O tempo de visita a uma flor foi de aproximadamente dois segundos, e o tempo de permanência em uma inflorescência variou de 20 a 40 segundos.

De acordo com a freqüência e o comportamento apresentados, as abelhas Xylocopa frontalis e $X$. griscesens foram consideradas polinizadores efetivas de G. sepium, enquanto Eulaema nigrita foi considerada como polinizadora ocasional.

Trigona spinipes Fab. apresentou dois comportamentos distintos, um para coleta de néctar e outro para coleta de pólen. No primeiro caso, $\boldsymbol{T}$. spinipes pousava sobre as alas e a quilha e caminhava em direção à região basal do cálice. Com o auxílio das peças bucais e das patas, perfurava o cálice e a corola e, introduzindo a língua neste orifício, tinha acesso ao néctar. Para a coleta de pólen, pousava sobre os botões em pré-antese, onde fazia uma pequena perfuração no ápice do botão para ter acesso às anteras, de onde coletava os grãos de pólen.

Apis mellifera L.visitava as flores de $\boldsymbol{G}$. sepium para coletar o néctar, pousando sobre alas e quilhas. Uma vez pousada, caminhava em direção à região basal da flor, posicionando-se lateralmente à quilha e introduzia a língua na região central do estandarte para ter acesso ao néctar. Por ser uma abelha de pequeno porte e, em conseqüência de seu posicionamento lateral, o mecanismo de exposição dos órgãos reprodutivos da flor não era acionado, não havendo contato com o corpo da abelha. De acordo com o comportamento apresentado, esta abelha e $\boldsymbol{T}$. spinipes foram consideradas como pilhadoras de néctar e/ou pólen de G. sepium.

Urbanus proteus L., embora tenha sido o visitante mais freqüente, visitava as flores em busca de néctar, porém não contatava as estruturas reprodutivas. Ao visitar uma flor, estes hesperiídeos pousavam sobre alas e quilha, introduzindo a probóscide na base dos elementos florais para alcançar o néctar. Durante a coleta deste recurso, o visitante não acionava o mecanismo de exposição dos órgãos reprodutivos florais, sendo então considerado como pilhador de néctar.

Os resultados obtidos nos diferentes experimentos de polinização estão agrupados na tabela 4, indicando que $G$. sepium é autoincompatível, formando frutos somente após a polinização cruzada, confirmando os dados apresentados por SIMONS \& DUNSDON (1987), onde esta espécie foi considerada xenogâmica obrigatória. Baixas taxas de frutificação foram observadas em condições naturais, indicando que houve falhas na polinização, que poderiam ser conseqüência do pequeno número de visitas dos agentes polinizadores. Frutos apomíticos e resultantes de autopolinização espontânea e manual não 
Tabela 4 - Experimentos de polinização em Gliricidia sepium. FL - número de flores tratadas, FR- número de frutos formados, \% porcentagem. Embrapa Semi-Árido, Petrolina-PE.

\begin{tabular}{llr}
\hline Experimentos de Polinização & FL/FR & $\%$ \\
\hline Controle & $30 / 9$ & 30,0 \\
Autopolinização espontânea & $36 / 0$ & 0,0 \\
Autopolinização manual & $30 / 0$ & 0,0 \\
Apomixia & $30 / 0$ & 0,0 \\
Xenogamia & $31 / 16$ & 51,6 \\
\hline
\end{tabular}

foram observados. Resultados semelhantes para esta espécie foram obtidos por AKEN'OVA \& SUMBERG (1986) em inflorescências protegidas. Assim, G. sepium foi considerada como uma espécie de polinização cruzada, apresentando $51,6 \%$ de frutos formados por xenogamia.

O número de frutos formados por inflorescência variou de um a cinco, sendo encontrados na população frutos com, no mínimo, duas e no máximo, oito sementes. A razão fruto/flor foi de 0,07 e a razão semente/óvulo foi de 0,53. Estes valores indicam que $\boldsymbol{G}$. sepium é uma espécie xenógama, uma vez que apresenta valores para as razões fruto/flor e semente/óvulo distantes de 1,0 (BAWA \& BUCKLEY, 1989).

\section{CONCLUSÕES}

Gliricidia sepium é autoincompatível, formando frutos somente após polinização cruzada. As abelhas Xylocopa griscesens e $X$. frontalis são consideradas como polinizadores efetivos desta leguminosa e Eulaema nigrita é considerada como polinizador ocasional. As abelhas Trigona spinipes e Apis mellifera e o hesperiídeo Urbanus proteus são considerados como pilhadores de néctar e/ou pólen.

\section{REFERÊNCIAS BIBLIOGRÁFICAS}

AGULHO, M.A., BRIZUELA, M.M., HOC, P.S., et al. Relacion unidade de polinizacion-visitantes florales en Vigna luteola (Leguminasae, Phaseoleae). Boletin de la Sociedad Argentina de Botanica, v.29, p.131-138, 1993.

AKEN'OVA, M.E., SUMBERG, J.E. Observations of the pollination systems of Gliricidia sepium. In: THAILAND INSTITUTE OF SCIENTIFIC AND TECHNOLOGICAL RESEARCH 1986, Bangkok. Nitrogen fixing tree: research report. Bangkok : TISTR, 1986. V.4, p.29-30.

BAWA, K.S., BUCKLEY, D.P. Seed: ovule rations, selective abortion and mating systems in Leguminosae. In: STIRTON, C.H., ZARUCHI, J.L., (ed). Advances in legume biology. Kew: Missouri Botanical Garden, 1989. p.243-262. (Missouri Botanical Garden - Monograph Systematics Botanic, 29). Trabalho apresentado no International Legume Conference, 2, Saint Louis, 1986.
BAWA, K.S., WEBB, C.J. Flower, fruit and seed abortion in tropical forest trees : implications for the evolution of paternal and maternal reproductive patters. American Journal of Botany, Columbus, v.71, p.736-751, 1984.

COBERT, S.A., WILLMER, P.G. Pollination of the yellow passion-fruit: nectar, pollen and carpenter bees. Journal of Agricultual Science, Cambrige, v.95, n.3, p.655-666, 1980.

DRUMOND, M.A., CARVALHO FILHO, O.M. de. Introdução e avaliação de Gliricidia sepium na região semi-árida do Nordeste Brasileiro. In: QUEIRÓZ, M.A. de, GOEDERT, C.O., RAMOS, S.R.R., (ed.) Recursos genéticos e melhoramento de plantas para o Nordeste brasileiro. (on line). Versão 1.0. Petrolina-PE: Embrapa Semi-Árido /Brasília-DF: Embrapa Recursos Genéticos e Biotecnologia, nov. 1999. Disponível via Word Wide Web http://www.cpatsa.embrapa.br. ISBN 85-7405-001-6

DUQUE, J.A. Gliricidia sepium (Jacq.) Steud. Disponível: site Horticulture Department at Purdue web. URL: http://www.hort.parde.edu/newcrop/duke _ energy/Gliricidia_ sepium Palavra-chave: Gliricidia sepium .Consultado em $2 \overline{3}$ ago. 1998.

FAEGRI, K., PIJL, L. van der. The principles of pollination ecology. Oxford: Pergamon, 1980. 244p.

FRANCO, A.L.M. Ecologia da polinização e biologia reprodutiva de sete espécies de Phaseoleae (Fabaceae). Campinas, SP, 1995. 123p. Tese (Doutorado em Biologia Vegetal) - Universidade Estadual de Campinas, 1995.

GENTRY, A.H. Coevolutionary patters in central american Bignoniaceae. Annals of the Missouri Botanical Garden, v.61, p.728-759, 1974a.

GENTRY, A.H. Flowering phenology and diversity in tropical Bignoniaceae. Biotropica, St. Louis, v.6, n.1, p.64-68, 1974b.

JANZEN, D.H. Synchronization of sexual reproduction of trees within the dry season in Central America. Evolution, Boulder, v.21, p.620-637, 1967.

JANZEN, D.H. Costa Rica natural history. Chicago: University of Chicago, 1983. 201p.

JOHANSEN, D.A. Plant microtechnique. New York : Mcgraw-Hill, 1940. 523p.

NEWSTROM, L.E., FRANKIE, G.W., BAKER, H.G. A new classification for plant phenology based on flowering patterns in lowland tropical rain forest trees at La Selva. Biotropica, St. Louis, v.26, n. 2, p.141-159, 1994.

PARROTTA, A.J. Gliricidia sepium (Jacq.) Walp. Gliricidia, mother of cocoa Leguminosae (Papilionoideae) Legume family. Rio Piedras : Institute of Tropical Forestry, 1992. 7p. (SO-ITF-SM-50)

RADFORD, A.E., DICKINSON, W.C., MASSEY, J.R., et al.. Vascular plant systematics. New York : Harper \& Row, 1974. 891p.

SIMONS, A.J., DUNSDON, A.J. Evalution of the potential for genetic improvement of Gliricidia sepium. Oxford : Oxford Foresty Institute, 1987. 10p. (Final report on ODA Foresty Research Project R4525).

SUMBERG, J.E. Note on flowering and seed production in a yong Gliricidia sepium seed orchard. Tropical Agriculture, Trinidad, v.62, n.1, p.17-24, 1985. 